\title{
SIMULATION OF CRISIS AFFECTING CRITICAL INFRASTRURES AND INDUSTRIAL PLANTS
}

\author{
Agostino G. Bruzzone $^{(\mathrm{a})}$, Marina Massei ${ }^{(\mathrm{b})}$, Riccardo di Matteo ${ }^{(\mathrm{c})}$, Matteo Agresta $^{(\mathrm{d})}$ \\ (a), (b) DIME University of Genoa, \\ (c) SIM4Future - ${ }^{(\mathrm{d})}$ Simulation Team \\ (a), (b) \{ bruzzone,massei, agresta $\} @$ itim.unige.it \\ (c) riccardo.dimatteo@sim4future.com - ${ }^{(\mathrm{d})}$ matteo.agresta@ simulationteam.com \\ (a), (b) Www.itim.unige.it - ${ }^{\text {(c) }}$ Www.sim4future.com - (d) Www.simulationteam.com
}

\begin{abstract}
This paper proposes a model for reproducing human behaviors and it is devoted to evaluate the operation performance in case of crisis with special attention to cases involving multiple actors such as fire-fighters, police, ambulances, civil protection and national reserve. The paper present the general scheme and the data structure used to conduct experiments related to cases of flooding and hazardous material spills in industrial and urban areas.
\end{abstract}

Keywords: Crisis Simulation, Interoperable Simulation, Industrial Crisis, Decision Support

\section{INTRODUCTION}

Today urban areas have growth up to incorporate many industrial facilities; due to this fact population density near to industrial plants dealing with hazardous material increased drastically, as well as concreting and land use; these factors increase the risks for population to be involved in crisis due to natural and/or man-made disasters (Mengfan 2016; Harding J.). It is evident that the urban framework introduces additional challenges for first responders in order to operate in the area and coordination issues turn to be even more complicated than in usual operations. These phenomena are highly stochastic, affected by multiple interactions of many entities over different layers as well as strongly influenced by external (e.g. weather conditions) and human factors; so it is evident the necessity to use Modeling and Simulation to model the different elements of the real systems (Longo 2013) and anticipate their behaviors (Longo et al. 2008). In this paper the authors propose part of a larger model in use to simulate crisis, able to reproduce industrial processes and phenomena ingenerating the crisis evolution as well as population behavior and first responder actions.

\section{CRISES IN INDUSTRIES AND CRITICAL INFRASTRUCTURES}

The authors have broad experience in dealing with simulation of a crisis including explosions, hazardous material spills, fires, flooding, terrorist attacks, etc. (Bruzzone et al., 2008, 2014, 2016b).

In facts during these crises, multiple actors are present and they need to be coordinated: fire fighters, police, ambulance \& health care facilities, national reserve, civil protection, etc.
This complex organizations could adopt different models for operating together and it is important to define the most effective and be aware of all the benefits from different structures, policies, regulations, operative plans and even technologies supporting these aspects. For instance, a major issue in a crisis dealing with an industry or a critical infrastructure is related to his impact on people; this means that transportation network could be compromised, often also power distribution is an issue to be solved as well as other urban layers. Moreover, gas distribution network in case of collapse of a critical infrastructure need to be secured in order to avoid further disasters or explosions. In this framework one of the major issue is related to people evacuation from dangerous areas (e.g. flooded or contaminated): this represent a major effort that could lead easily with hundreds of families or thousands of people to be moved within a town during chaotic moments. Another crucial aspect is related to the time scale that requires to address not only first response, but also several actions on short terms, required by the actors that deal with public safety and security.

The authors have currently specific simulation models and libraries for addressing these aspects including IACGF, ST_CIPROS, ST_CRISOM, PONTUS, etc. (Bruzzone et al.,2014, 2016a, 2017a). These simulators adopt interoperability through High Level Architecture Standard in order to guarantee the possibility to federate together different models and distributed with other systems (Kuhl et al.2000); in this way it is possible to substitute the hazardous material spill model for realtime simulation devoted to training, with high fidelity simulators devoted to reproduce the contamination on the area for analyzing specific scenarios; at the same time, reliable models for fast time simulation could be used to run multiple replications in order to finalize in a preventive way the Standing Operation Procedures (SOP) respect specific period of the year (Bruzzone et al. 1996, 2017c). Interoperability is fundamental, it is useful also for evaluating the coordination respect different actors; indeed by this approach different simulators could be federated allowing each of the actor to play a scenario with others and to be trained on their Command and Control (C2) systems; from this point of view there are several researches for defining capabilities, new guidelines and standards to reinforce use of simulation within different major actors during a crisis. 


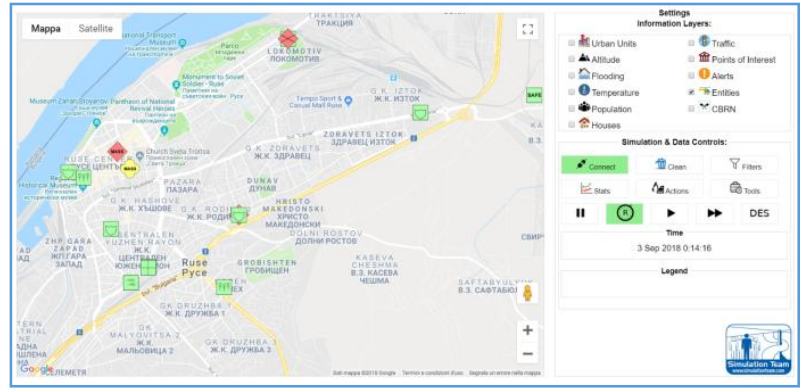

Fig.1 ST_CRISOM Simulation

The authors have recently completed different experimentations on projects dealing with crisis. First mention is about Decision Theater where different simulation models have been used such as ST_CRISOM, CIPROS, PONTUS within the Smart City funding program; the main crisis event was related to flooding in urban area with the possibility to diffuse contamination by depleting chemical tanks and facilities in industrial areas. In this case, the simulator addressed different criticalities:

- emergency management and evacuation considering the impact of flooding and contaminated waters,

- $\quad$ strategic planning in the given area to secure the situation by investments in infrastructures,

- industrial facilities additional safety elements,

- $\quad$ preventive crisis plans for first responders.

It is evident that this approach support also safety engineering and analysis devoted to prevent accidents and mitigate effect of crises. The experimentation allowed also to test decision makers' needs and expectations together with the City Authority and it was applied to Genoa case (major Italian port Town with less than a million inhabitants). The research tested also the possibility to interconnect the simulator with social networks to perform on-line acquisition of information coming directly from people (e.g. manhole blockage, river level, traffic jam, visible contamination, water level, etc.); the developed model fuses these information with other available data and spreads the input over time and space considering the constraints (Bruzzone et al.2017b).

Another application case is currently related to researches about use of these models for supporting collaboration between military units and civil agencies during such crises (Bruzzone et al. 2017a).

Also in these case ST_CRISOM, CRISOM, PONTUS, CIPROS of Simulation Team were tested and federated with other systems (i.e. jcats, pac, cora, hpac, dm, sword, arcaria-sword) by using different FOM popular among defense applications. In this case population has owned and controlled by Simulation Team as well as some specific crisis (e.g. flooding and industrial contamination or hazardous material spills).

Currently the authors are working in using these simulators in application to industrial cases to evaluate the impact of hazardous material spills and corresponding preventive actions and emergency management. The recent collapse of the "Morandi Bridge", a tragic event affecting Genoa (Harding 2018), makes the ST_CRISOM model, already tuned for flooding from previous Smartcity project, an additional way to provide support for mitigating the crisis and possibly restoring the affected areas. The bridge was an actual critical infrastructure, quite large, connecting Genova with its port. By the way, this specific area of the town statistically collected the highest rainfall in whole Italy (Acquaotto et al.2017; Faccini et al.2018). In addition the bridge was crossing a very high density populated district and the major industrial zone with major facilities (e.g. Ansaldo Energy). This case introduces the destruction of a critical infrastructure that impacts the Port Terminals, the transportations over the region (East to West and vice versa) and in some way the whole mobility.

Over 600 people evacuated and large industrial complex need to be reorganized and relocated. In case of heavy rain falls, the ruins on the river could potentially increase flooding risk as well potential contamination of waters/mud, being the fall season the most dangerous period on this area. Inhabitants' high density, heavy concreting and soil consumption affect the simulation evolution through water speed as well as the impact on the river bed and channels created by urbanization (Duley 1939; Chanson 2004). Currently the authors are working on this case to evaluate alternative solution for transportations, alternative actions to address different risks taking care of preventive and mitigation effects; this paper presents some of the data structures used to model this case, especially ST_CRISOM simulator (Simulation Team Crisis Simulation, Organization and Management) that reproduces dynamics of a given complex scenario where a crisis evolves.

\section{CRISIS SIMULATION}

ST_CRISOM considers the human behavior of the population in terms of evacuations, reactions due to the emergency as well as to human factors (fear, stress, fatigue and aggressiveness). ST_CRISOM is a stochastic hybrid interoperable simulator using intelligent agents; indeed ST_CRISOM combines discrete event simulation of operations with continuous simulations of physical systems such as flooding.. Indeed ST_CRISOM uses the IA-CGF (Intelligent Agent Computer Generated Forces) to reproduce both civilian Populations as well as First Responders and Military units, Health Care, Civil Protection Agents \& Public Infrastructures (Bruzzone 2013). CRISOM acts as a NCF (Non Conventional Framework) for IA-CGF and allows to reproduce Flooding Scenario and Industrial Contamination as well as Hazardous Material Spill over regional areas and impact on Town, Industrial Facilities and Critical Infrastructures. ST_CRISOM adopts HLA (e.g. evolved HLA IEEE1516-2010) standard to be federated with other Simulators using different RTIs.(e.g. Pitch RTI 5.3.2.1). 


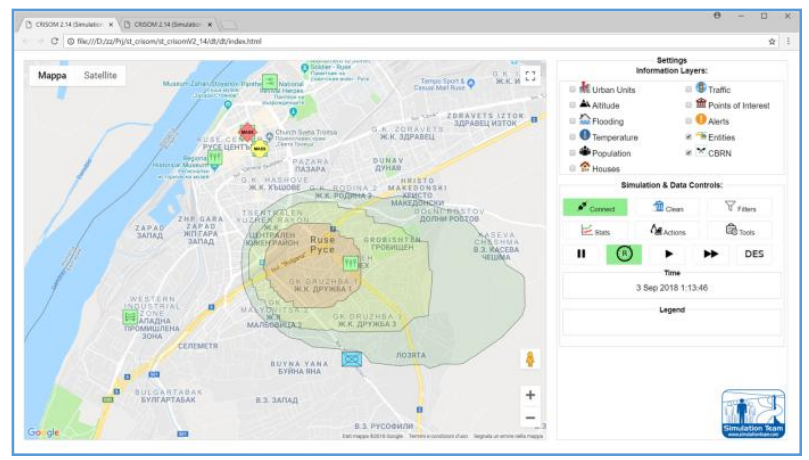

Fig.2 ST_CRISOM Simulation

\section{PLAYERMESSAGE}

ST_CRISOM uses a specific Interaction, defined PlayerMessage, for managing communications, lists and reports with other tools or simulators that have constraints is fully access HLA features.

\section{Player Message in the FOM}

<interactionClass>

$<$ name $>$ PlayerMessage $</$ name $>$

$<$ sharing $>$ PublishSubscribe $</$ sharing $>$

$<$ transportation $>$ HLAreliable $</$ transportation $>$

$<$ order $>$ Receive $<$ /order $>$

$<$ semantics $>$ CIPROS

player

message. $</$ semantics $>$

$<$ parameter>

$<$ name $>$ Time $</$ name $>$

$<$ dataType $>$ HLAfloat64Time</dataType $>$

<semantics>

Time when the report has to be sent (if the time is not specified the report has to be delivered as soon as possible) or an order/instruction has to be executed (if the time is not specified the order has to be executed as soon as possible).

Please note: The same info proposed here is available in the PlayerMessage content $!</$ semantics $>$

$</$ parameter $>$

$<$ parameter $>$

$<$ name $>$ Source $</$ name $>$

$<$ dataType $>$ HLAunicodeString $</$ dataType $>$

$<$ semantics $>$ The Player who has to execute

the order or the sender of the report (Player ID).

Please note: The same info is available in the PlayerMessage content $!</$ semantics $>$

$</$ parameter $>$

$<$ parameter $>$

$<$ name $>$ Content $</$ name $>$

$<$ dataType $>$ HLAunicodeString $</$ dataType $>$ $<$ semantics $>$ the content of the message.

(JSON format) $</$ semantics $>$ $</$ parameter $>$

\section{$</$ interactionClass $>$}

\section{Player Message Examples}

Examples of Format used by ST_CRISOM through Player Message in order to transmit to other systems specific info:
Code $36 \quad$ Status Update of Critical Infrastructure Update on the status of an industrial plant, tank or critical infrastructure during the crisis

[report id][unit id][time][location][Status: 0-100\%][B]

\# [order id], *Status Update, [unit_id], [time], [location], [Status: 0-100\%], [free text] \$

\section{Code 37 Weather Update}

Update on weather situation

[report id][type][pdi_id][time][location][wind speed ][wind direction][rain intensity $\mathrm{mm} / \mathrm{h}]$ [snow intensity $\mathrm{mm} / \mathrm{h}][$ range1][mitigation 1][range 2][mitigation 2][range3][mitigation 3][fog/visibility m][B]

\# [order id], *Weather Update, 7,[PDI Id], [time], [location], [wind speed: $\mathrm{m} / \mathrm{s}$ ], wind direction, degrees], [rain intensity $\mathrm{mm} / \mathrm{h}$ ], snow intensity $[\mathrm{mm} / \mathrm{h}$ ], [range 1 , $\mathrm{km}$ ], [mitigation factors 1, 0.0-1.0], range 2, $\mathrm{km}$ ], [mitigation factors $2,0.0-1.0$ ], [range $3, \mathrm{~km}$ ] [mitigation factors 3, 0.0-1.0], [visibility, $\mathrm{m}$ ], [free text] $\$$

\section{Code $38 \quad$ River Report}

Report on River status during the crisis

[report id][type][pdi_id][time][location][water level][water limiti] [B]

\# [order id], *Weather Update, 2, [PDI Id], [time], [location], [water level, m], [water limit, m], [free text] $\$$

\section{Code $39 \quad$ People Report}

Report on Refugees, Evacuated People, etc.

[report id][source_id][type of report]time][location] [number of refugees][adult males][adult females][young people][people with impediments][Number of Red Tags][Number of Yellow Tags][B]

\# [order id], *Crisis Report, [source_id],[type report: Refugees, Evacuation from Crisis Area Level A, Evacuation from Crisis Area Level B, Evacuation from Crisis Area C], [time], [location], [number of refugees],[adult males],[adult females],[young people],[people with impediments], [Number of Red Tags], [Number of Yellow Tags], [Free Text]\$

\section{Code $40 \quad$ Medical Evacuation Report}

Report on Injured People and casualties as well as on arrivals on hospital

[report id][source_id][type of report]time][location] [Number of Red Tags][Number of Yellow Tags] [Number of Green Tags] [Number of Wounded][Number of Casualties][B]

\# [order id], *Medevac Report, [source_id], [time], [location], [Number of Red Tags], [Number of Yellow Tags], [number of Green Tags],[Number of Wounded People], [Number of Deads][Free Text]\$ 
Code $41 \quad$ Single People Report

List of people during the simulation.

[report id][peo_id][time][location][health status][age][gender][impedements][condition][fullname ][education level][social status][religion][ethic group][tribe][political party][B]

\# [order id], * Singel People Report, [peo_id], [time], [location],

[health status: 0-100],[age],[gender: 1 male, 2 female]],[impedements:

invalidity percentuage][condition: regular, to be evacuated, escaped],[fullname],[education level: String][social status: String][religion:0-8][ethic group: String][tribe: String][political party: String]

[free text] \$

\section{Flooded Area Report}

Report on flooded areas including contamination level

[report id][type][pdi_id][time][corner1][corner 2][water level][water type] [B]

\# [order id], *Flooding Update, 2, [PDI Id], [time], [corner1], [corner2], [water level, m], [water type: clean-mud-contaminated-highly contaminated], [free text] \$

\section{CRISOM Input Data}

Please check the Annex Directories with file examples

\section{DEM/DTM File}

Digital Elevation/Terrain Model.

Format: TIFF (GeoTIFF)

CRS (Coordinate Reference System): EPSG:4258

Step: $<20 \mathrm{~m}$

\section{Population File}

Urbanistic Unit Population.

Format: csv

Structure:

\begin{tabular}{|l|l|l|l|l|l|l|l|l|l|}
\hline ID (1) & Name & $\begin{array}{l}\text { Sex } \\
(2)\end{array}$ & $\begin{array}{l}\text { Nationality } \\
(3)\end{array}$ & Age 0-4 & Age 5-9 & $\ldots$ & $\begin{array}{l}\text { Age over } \\
100\end{array}$ & Total & $\begin{array}{l}\text { Average } \\
\text { Age }\end{array}$ \\
\hline 1 & Crevari & M & POLAND & 2 & 2 & $\ldots$ & 0 & 8 & 43,5 \\
\hline
\end{tabular}

(1) Urbanistic Unit ID (only one for each unit)

(2) Value: M / F

(3) Value From the list of Nations (e.g. AFGHANISTAN, ALBANIA, ALGERIA, ANGOLA, ..., ARGENTINA, ARMENIA, AUSTRALIA, AUSTRIA, ..., BELGIUM,....etc.)

\section{Educational Level File}

Number of people for educational Level

Format: csv

\section{Structure:}

\begin{tabular}{|l|l|l|l|l|l|l|l|}
\hline \hline Country (1) & $\begin{array}{l}\text { Country } \\
\text { (2) }\end{array}$ & Year & $\begin{array}{l}\text { Population 0- } \\
14 \text { years old }\end{array}$ & & $\begin{array}{l}\text { Primary } \\
\text { School }\end{array}$ & $\begin{array}{l}\text { Secondary } \\
\text { School }\end{array}$ & University \\
\hline ARGENTINA ARG & 2015 & 10003060 & 630038 & 11750805 & 16010261 & 4066270 \\
\hline
\end{tabular}

(1) From the Country List

(2) Argentina -> ARG
GDP per capita

GDP per capita for each country

Format: txt

Structure:

ARGENTINA

$\$ 20,100$ (2016 est.)

\section{GINI Index}

Gini index for each Country

Format: txt (ASCII)

Structure:

ARGENTINA

\section{Infrastructures Description}

Critical Infrastructure

Format: csv

Structure:

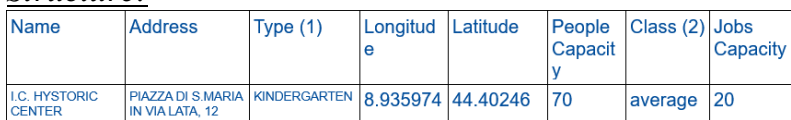

(1) The type: "Kindergarten", "Primary School", "Secondary School", "High School", "Private Kindergarten", " Private Primary School ", "Private Secondary School", "Private High School", "University", "museum", "park", "villa", "forte", "theater", "cinema", "beach", "caffe", "stadium", "shop", "trade center", "hospital", "police station", "fire station", "bank", "parking"

(2) "low", "average", "high"

Optional Fields:

\begin{tabular}{|l|l|l|l|l|l|}
\hline \hline Hierarchy & Municipality & Province & Phone Number & Area & District \\
\hline N.D. & Genova & GE & N.D. & N.D. & N.D. \\
\hline
\end{tabular}

Natality

Sons Number per woman for each Country

Format: csv

Structure:

ARGENTINA,ARG,2015,2.3080001

\section{Political Preferences}

The preferred Political Parties (Chance to vote) for Sex $(\mathrm{M} / \mathrm{F})$, age groups $(25-29,29-34 \ldots)$, educational level

Format: csv

\begin{tabular}{|c|c|c|c|c|c|c|c|}
\hline \multicolumn{8}{|c|}{ Structure: } \\
\hline & Party 1 & Party 2 & Party 3 & Party 4 & Party 5 & Party 6 & Party 7 \\
\hline & & & & & & & \\
\hline $\mathrm{M}$ & 0.1 & 0.1 & 0.1 & 0.1 & 0.4 & 0.1 & 0.1 \\
\hline \begin{tabular}{|l} 
F \\
\end{tabular} & 0.4 & 0.1 & 0.1 & 0.1 & 0.1 & 0.1 & 0.1 \\
\hline \multirow{2}{*}{$0-4$} & & & & & & & \\
\hline & \multicolumn{7}{|c|}{. } \\
\hline 50-54 & 0.1 & 0.2 & 0.1 & 0.2 & 0.1 & 0.1 & 0.2 \\
\hline \multicolumn{8}{|l|}{$\ldots$} \\
\hline & & & & & & & \\
\hline $\begin{array}{l}<14 \text { years } \\
\text { old }\end{array}$ & 0 & 0 & 0 & 0 & 0 & 0 & 0 \\
\hline- & 0.1 & 0.2 & 0.1 & 0.2 & 0.1 & 0.1 & 0.2 \\
\hline \begin{tabular}{|l|} 
Primary \\
School
\end{tabular} & 0.1 & 0.2 & 0.1 & 0.2 & 0.1 & 0.1 & 0.2 \\
\hline \begin{tabular}{|l|} 
High \\
School
\end{tabular} & 0.1 & 0.2 & 0.1 & 0.2 & 0.1 & 0.1 & 0.2 \\
\hline \begin{tabular}{|l} 
University \\
\end{tabular} & 0.1 & 0.2 & 0.1 & 0.2 & 0.1 & 0.1 & 0.2 \\
\hline
\end{tabular}




\section{Population Distribution}

Population distribution in the urbanistic unit (optional), if the units are not included in the file, or the file miss, the population (houses distribution) is consider uniform. Format: JSON

Structure:

$\{$ "features": [

\{"id":29,"name":"Angeli","population_center":[8.90664 4,44.415041], "population_sigma":[1.0,0.6]\},

\{"id":58,"name":"Apparizione","population_center":[8. 993217,44.403883], "population_sigma":[0.2,0.5]\}]\}

The Fields:

- id: urbanistic unit ID

- name: urbanistic unit name

- population_center: the coordinates of the unit point with the maximum population density

- population_sigma: population distribution efficacious value

\section{Population Incomes}

Urbanistic unit average income

Format: csv

Structure:

Urban Unit, Average Income

Example:

$2,19.93$

$3,16.446$

$4,19.803$

$5,19.165$

$6,24.061$

\section{Public Events}

Week Events affecting Population

Format: csv

Structure:

\begin{tabular}{|l|l|l|l|l|l|l|l|}
\hline \hline Type & $\begin{array}{l}\text { Kind of } \\
\text { Place }\end{array}$ & Longitude & Latitude & $\begin{array}{l}\text { Day of the } \\
\text { Week }\end{array}$ & $\begin{array}{l}\text { Starting } \\
\text { Hour }\end{array}$ & $\begin{array}{l}\text { Duration } \\
\text { [hours] }\end{array}$ & Description \\
\hline $\begin{array}{l}\text { entertain } \\
\text { ment }\end{array}$ & stadium & 8.95246 & 44.41645 & 6 & $12: 00: 00$ & 2 & $\begin{array}{l}\text { football } \\
\text { event }\end{array}$ \\
\hline
\end{tabular}

\section{$\underline{\text { Religion Compatibility }}$}

Compatibility defining the chance to be friends or create family

\section{Format: csv}

\section{Structure:}

\begin{tabular}{|l|l|l|l|l|}
\hline \hline & CHRISTIAN & MUSLIM & UNAFFIL & HINDU \\
\hline CHRISTIAN & 1.0 & 0.5 & 0.5 & 0.5 \\
\hline MUSLIM & 0.5 & 1.0 & 0.5 & 0.5 \\
\hline UNAFFIL & 0.5 & 0.5 & 1.0 & 0.5 \\
\hline HINDU & 0.5 & 0.5 & 0.5 & 1.0 \\
\hline
\end{tabular}

\section{$\underline{\text { Religions }}$}

Country Population Percentage of each religion.

Format: txt

Structure:

COUNTRY, PERCENT CHRISTIAN, PERCENT MUSLIM, PERCENT UNAFFIL., PERCENT HINDU, PERCENT BUDDHIST, PERCENT FOLK RELIGION, PERCENT OTHER RELIGION, PERCENT JEWISH
Example

AFGHANISTAN,0.1,99.7,0.1,0.1,0.1,0.1,0.1,0.1

ALBANIA, 18,80.3,1.4,0.1,0.1,0.1,0.2,0.1

ALGERIA, 0.2,97.9,1.8,0.1,0.1,0.1,0.1,0.1

$\cdots$

\section{Rivers \& Sewerage}

Rivers, Aquifer, Sewerage and Manholes of the scenario

Format: JSON

Structure:

$\{$ "node_id": 0 ,

"node_coordinates": [

44.39431220,

8.942613601

], "node_links": [

"link_id": 7

\} ] \}, \{

"node_id": 1,

"node_coordinates": [

44.407359497,

8.9502578973

],

"node_links": [

\{

"link id": 7

\} ,

"link_id": 8

\} ,

\{

"link_id": 114

\} ] ],

"links": [

\{ "link_id": 0,

"node_1": 18,

"node_2": 20,

"depth": 4,

"width": 50,

"type": "normal",

"distance": 303.501

\} ,

"link_id": 1,

"node_1": 180,

"node_2": 79,

"depth": 1,

"width": 3 ,

"type": "underground",

"distance": 1161.451

\}] \}

The Fields:

node_id: node ID

node_coordinates: node coordinates

node_links: links connected to the node

link id: link ID

node_1, node_2: the nodes connected by the link depth: average depth of the river 
width: average width of the river bed type: link type ( normal/underground ) distance: distance of the link in meters

\section{$\underline{\text { Roads }}$}

The roads of the scenario Format: JSON

\section{Structure:}

\{ "nodes": [

$\{$ "node_id": 0,

"node_coordinates": [

44.41520655,

8.707437515

],

"isolated": false,

"node_links": [

\{

"link_id": 195

\} ,

\{ "link_id": 225

\} ] \},

$\{\quad$ "node_id": 1 ,

"node_coordinates": [

44.42575053,

$8.736963272 \quad]$,

"isolated": false,

"node_links": [

\{

"link_id": 10

\}

,

"link_id": 195

\} ] ] ,

"links": [

$\{\quad$ "link_id": 281,

"node_1": 55 ,

"node_2": 62,

"type": "normal",

"distance": 3525.494,

"direction": 0

\} ,

\{

"link_id": 1,

"node_1": 200,

"node_2": 88,

"type": "normal",

"distance": 182.210,

"direction": 0

\} ] \}

The Fields:

node_id: node ID

node_coordinates: node coordinates

node_links: vector of links connected to the node link_id: link ID

node_1, node_2: the nodes connected by the link type: type of the road (normal/highway/railway)

direction: direction of the traffic:

0 - bidirectional

1 - from node 1 to node 2
-1 - from node 2 to node 1

Terrain Type

Terrain Type

Format: TIFF (GeoTIFF)

CRS (Coordinate Reference System): EPSG:3035

The Terrain Type must be compatible with the format used in the Copernicus Project (www.copernicus.eu)

Urban Areas

Urbanistic unit (polygons)

Format: GeoJSON

Structure:

\{"type":"FeatureCollection","features":[ [ "type":"Featur e","geometry": \{ "type":"Polygon","coordinates":[[[8.83 $628,44.423768,0],[8.83644,44.423748,0],[8.836494,44$. 423726,0],[8.836726,44.423661,0]]]\},"properties": \{"str oke":"\#555555","stroke-width":2,"stroke-

opacity": 1 ,"fill":"\#555555","fill-

opacity":0.5,"name":"Porto","id":0\}\}]\}

\section{Weather Forecasts}

Weather Forecast

Format: csv

Structure:

\begin{tabular}{|l|l|l|l|l|l|}
\hline $\begin{array}{l}\text { Weather } \\
\text { Station }\end{array}$ & Date \& time & $\begin{array}{l}\text { Rain intensity } \\
{[\mathrm{mm} / \mathrm{h}]}\end{array}$ & $\begin{array}{l}\text { Temperature } \\
{[\mathrm{C}]}\end{array}$ & $\begin{array}{l}\text { Wind } \\
\text { speed }[\mathrm{m} / \mathrm{s}]\end{array}$ & Wind Direction \\
\hline 1 & $\begin{array}{l}12 \mathrm{Feb} 2018 \\
07: 00: 00\end{array}$ & 10 & 12 & 3 & 90 \\
\hline
\end{tabular}

\section{Weather Statistics}

Typical values of the temperature, wind direction Format: csv

Structure:

\begin{tabular}{|l|l|l|l|}
\hline Weather Station (1) & $\begin{array}{l}\text { Temperature Correction } \\
\text { Hourly (2) }\end{array}$ & Wind Direction (3) & $\begin{array}{l}\text { Wind Speed (4) } \\
{[\mathrm{m} / \mathrm{s}]}\end{array}$ \\
\hline 1, Christopher & $-3.6,-3.6,-3.6,-3.4$, & $270,180,090,090$, & $6,6,5,4$, \\
Columbus, Airport, & $-3.7,-3.7,-2.8,-1.7$, & $090,090,090,090$, & $3,2,1,1$, \\
$8.847598, \quad 44.414878$ & $-0.6,+1.0,+3.2,+3.4$, & $090,180,180,270$ & $4,5,5,5$ \\
& $+3.7,+2.9,+1.8,+1.7$, & & \\
& $+1.6,+0.6,-0.6,-1.4$, & & \\
& $-2.7,-3.2,-3.5,-3.7$ & & \\
\hline
\end{tabular}

1) Weather Station that gives the weather forecast:

ID, name, description, longitude, latitude

2) Change in temperature during a day compared to average temperature

3) Typical Wind Direction in each month of the year

3) Typical Wind Speed in each month of the year

\section{Work and Commercial Activities}

Workplace and attractiveness number of each urbanistic unit

Format: csv

Structure:

\begin{tabular}{|l|l|l|l|l|l|l|l|}
\hline $\begin{array}{l}\text { Unit } \\
\text { id }\end{array}$ & $\begin{array}{l}\text { Unit } \\
\text { Name }\end{array}$ & $\begin{array}{l}\text { Workplace } \\
\text { High }\end{array}$ & $\begin{array}{l}\text { Workplace } \\
\text { Average }\end{array}$ & $\begin{array}{l}\text { Workplace } \\
\text { Low }\end{array}$ & $\begin{array}{l}\text { Attraction } \\
\text { High }\end{array}$ & $\begin{array}{l}\text { Attraction } \\
\text { Average }\end{array}$ & $\begin{array}{l}\text { Attraction } \\
\text { Low }\end{array}$ \\
\hline 0 & Porto & 750 & 1800 & 450 & 1.5 & 2 & 2 \\
\hline
\end{tabular}

The Fields:

Id and Name of urbanistic unit

Workplace number of employed in this area subdivided in terms of income groups:

low/average/high

Attractiveness of urbanistic unit: 0 - doesn't attract, 1 - average level, $>1$ - high level 


\section{CONCLUSIONS}

The paper proposes an effective use of simulation to address crisis impacting urban areas in relation to critical infrastructure and industrial facilities; it is proposed an innovative agent-driven interoperable hybrid stochastic simulation and data structures to support interoperability and connection with other systems and simulators. The proposed approach represents a good opportunity to use simulator in synergy with other models, tools and systems to enhance training, planning, operational support as well as safety engineering. Currently the authors are using it for multiple case studies, extending further its potential and conducting additional experimentation on interoperability with other systems.

\section{REFERENCES}

Acquaotta, F., Faccini, F., Fratianni, S., Paliaga, G., \& Sacchini, A. (2017). Rainfall intensity in the Genoa Metropolitan Area (Northern Mediterranean): secular variations and consequences. Weather.

Bruzzone A.G., Maglione G.L., Agresta M., Di Matteo R., Nikolov O., Pietzschmann H., David W. (2017a) "Population Modelling for Simulation of Disasters \& Emergencies Impacting on Critical Infrastructures", Proc.of WAMS, Florence, September

Bruzzone A.G., David W., Agresta M., Iana F. Martinesi P., Richetti R. (2017b) "Integrating Spatial Analysis, Disaster Modeling and Simulation for Risk Management and Community Relisience on Urbanized Coastal Areas", Proc. of 5th Annual Interagency, Interaction in Crisis Managements and Disaster Response, CMDR, June 1-2

Bruzzone, A.G., Agresta, M., Sinelshchikov, K. (2017c). Simulation as decision support system for disaster prevention. SESDE 2017, Barcelona, Spain

Bruzzone A.G., Longo F., Massei M., Nicoletti L., Agresta M., Di Matteo R., Maglione G.L., Murino G., Antonio Padovano A. (2016a) "Disasters and Emergency Management in Chemical and Industrial Plants: Drones simulation for education \& training", Proc. of MESAS, Rome, June 15-16

Bruzzone A.G., Massei M., Di Matteo R., Agresta M., Franzinetti G., Porro P. (2016b) "Modeling, Interoperable Simulation \& Serious Games as an Innovative Approach for Disaster Relief', Proc.of I3M, Larnaca, Sept. 26-28

Bruzzone A.G., Cirillo L., Longo F., Nicoletti L.(2015) "Multi-disciplinary approach to disasters management in industrial plants", Proc.of the Conference on Summer Computer Simulation, Chicago, IL, USA, July, pp. 1-9

Bruzzone A.G., Frascio M., Longo F., Chiurco F., Zanoni S., Zavanella L., Fadda P., Fancello G., Falcone D., De Felice F., Petrillo A., Carotenuto P. (2014) "Disaster and Emergency Management Simulation in Industrial Plants", Proceedings of EMSS2014, Bordeaux, France, September
Bruzzone, A. G. (2013). Intelligent agent-based simulation for supporting operational planning in country reconstruction. International Journal of Simulation and Process Modelling, 8(2-3), 145159.

Bruzzone A.G., Scavotti, A., Massei, M., Tremori, A.(2008) "Metamodelling for analyzing scenarios of urban crisis and area stabilization by applying intelligent agents", Proceedings of 20th European Modeling and Simulation Symposium, Amantea, Italy, September 17-19, pp.521-526

Bruzzone A.G., Giribone P., Mosca R. (1996) "Simulation of Hazardous Material Fallout for Emergency Management During Accidents", Simulation, vol. 66, no.6, June, 343-355

Chanson, H. (2004). Hydraulics of open channel flow. Elsevier.

Duley, F. L., \& Kelly, L. L. (1939). Effect of soil type, slope, and surface conditions on intake of water.

Faccini, F., Luino, F., Paliaga, G., Sacchini, A., Turconi, L., \& de Jong, C. (2018). Role of rainfall intensity and urban sprawl in the 2014 flash flood in Genoa City, Bisagno Catchment (Liguria, Italy). Applied Geography, 98, 224-241.

Harding J. (2018)"CCTV shows Genoa bridge collapse”, BBC News, August 21

Kuhl, F., Dahmann, J., \& Weatherly, R. (2000). Creating computer simulation systems: an introduction to the high level architecture. Upper Saddle River: Prentice Hall PTR.

Longo, F. 2013. On the short period production planning in industrial plants: A real case study. International Journal of Simulation and Process Modelling, vol. 8, no. 1, pp. 17-28.

Mengfan Z. (2016) "Tianjin chemical blast: Deadly disaster marked one year on", BBC News, August 12.

Ören, T., Longo, F., 2008. Emergence, anticipation and multisimulation: Bases for conflict simulation. 20th European Modeling and Simulation Symposium, EMSS 2008, pp. 546. 